\title{
Karton Ambalaj Üretiminde Ofset Baskı Sonrası Selofan Uygulamasının Renk Değişimine Etkisinin İncelenmesi
}

\author{
Zafer ÖZOMAY ${ }^{1} \&$, Lutfi ÖZDEMIR ${ }^{2}$ \\ ${ }^{1}$ Basım Teknolojileri Bölümü, Uygulamalı Bilimler Yüksekokulu, Marmara Üniversitesi, İstanbul, Türkiye \\ ${ }^{2}$ Basım ve Yayın Teknolojileri Bölümü, TBMYO, Marmara Üniversitesi, İstanbul, Türkiye \\ $\bowtie$ : ozomay@marmara.edu.tr, (iD)10000-0002-7650-733X, (iD)2 0000-0002-0827-8037
}

Geliş (Received): 26.08.2020

Düzeltme (Revision):30.08.2020

Kabul (Accepted): 03.11.2020

\section{Öz}

Baskı sonrası uygulamalarında selofan kullanımı, ürünün mukavemet özelliklerinin arttırmada ve görsel kalitesinin korunmasında önemli bir yere sahiptir. Karton ambalaj üretiminin büyük çoğunluğunda; sevkiyat, depolama ve satış sürecinde ambalajın yapısal özelliklerini koruması amacıyla selofan kaplaması uygulanmaktadır. Doğru parametreler kullanılmadan kaplanan selofan; nitro dayanımı düşük mürekkeplerde renk farklarına neden olmaktadır. Oluşan olumsuz durumlar ambalaj kalitesini etkilemekte ve üretici ile müşteri arasında itilaflara sebep olmaktadır. Bu çalışmada, gerçek üretim şartlarında karton ambalaj bakısı yapılan üretim tesisinde, hazırlanan test skalası basılmış kartonlar üzerine parlak ve mat selofan uygulaması yapılmıştır. ISO12647-2'ye uygun gerçekleştirilen baskılar üzerine homojen uygulanan selofanın öncelikle görsel kontrolü yapılmıştır. Densitometrik ve spektrofotometrik ölçümler yapılarak; nokta kazancı, renk değişimi ve renk evrenleri ölçümlenerek bu değerler grafikler ve tablolar ile inceleme sonuçları verilmiştir. Sonuç olarak; karton ambalaj baskısı üzerine uygulanan selofan kaplamalarının, nokta kazancı değerlerini artırdığı, renk evrenini genişlettiği, özellikle parlak selofan uygulamasının daha geniş renk evreni sağladığı tespit edilmiştir.

Anahtar Kelimeler: Karton Ambalaj, Nokta Kazanc1, Ofset Bask1, Renk, Selofan

\section{Investigation Of The Effect Of Cellophane Application On Color Change After Offset Printing In Cardboard Packaging Production}

\begin{abstract}
The use of cellophane in post-printing applications has an important role in increasing the strength properties of the product and maintaining its visual quality. In the majority of cardboard packaging production, cellophane coating is applied in order to protect the structural features of the packaging during the shipment, storage and sales process. Cellophane coated without using the right parameters causes color differences in inks with low nitro resistance. Adverse situations affect the quality of the packaging and cause entanglements between the manufacturer and the customer. In this study, glossy and matte cellophane was applied on the test scale printed cartons prepared in the production facility where cardboard packaging was maintained under real production conditions. According to iso12647-2 prints, homogenous cellophane was first controlled visually. Densitometric and spectrophotometric measurements were made; dot gain, color change and color universes were measured and these values were examined with graphs and tables. As a result, it was determined that cellophane coatings applied on cardboard packaging printing increased dot gain values, expanded the color universe, and especially bright cellophane application provided a wider color universe.
\end{abstract}

Keywords: Cellophane, Color, Dot Gain, Offset printing, Packaging

\section{GíRiş}

Matbaacılığın, ilk kullanılmaya başlandığı tarihten bu yana baskı işlemleri açısından birçok yenilik üretilmektedir [1]. Özellikle bask1 öncesi, bask1, bask1 sonrası teknolojileri ile büyük bir değişim göstermiştir. [2]. Basım sektöründe faaliyet gösteren her firma, ürün özelliklerini optimize ederek hem ürün özelliklerini geliştirmeyi amaçlamakta hem de maliyet konusunda üreticiye büyük katkı sağlamaktadır. Selofan en eski film kaplama yöntemlerinden ve film tiplerinden biridir. [3]. Kâğıdın hassas ve deformasyona müsait yapısı nedeniyle bu uygulama, baskı ürünlerinin 1şı̆̆a, yırtılmaya, suya ve benzer diğer dış etkenlere karşı daha dayanıklı olması için yapılmaktadır [4, 5]. Karton ambalajların yanı sıra, kitap ve defter kapakları ve kartvizitlerin daha uzun ömürlü ve dayanıklı olmalarını sağlar [6]. Selofan üretimi için odundan elde edilen selüloz kullanılmaktadır [7]. Odundan elde edilen selüloz daha sonra kimyasallarla reaksiyona sokularak "viskoz" ve daha sonra "selüloz hidrat " haline getirilerek film şeklinde preslenir. Bu durumdaki film suya karşı hassastır [8]. Ambalaj kartonu üzerinde koruyucu olarak kullanmak için çeşitli laklarla yüzeyi kaplanır [9, 10]. Böylelikle hem suya dayanıklı hale gelir, hem de ısıl yapışma özelliği kazanır. Özel efektler 
oluşturmak için zaman zaman yapılandırılmış yüzeylere sahip lamine filmler uygulanır [11]. Bask1 tamamlandıktan sonra hemen her ürün çeşitli baskı sonrası işlemlere tabi tutulmaktadır. Karton ambalaj üretiminde en yaygın olarak kullanılanı ise selofan kaplamadır [12, 13]. Baskı ürünlerini suya, 1şığa ve diğer dış etkenlere karşı korumak amacıyla uygulanan bir laminasyon yöntemidir. Ürünlerin üzerine uygulanan çok ince plastik bir tabaka formundadır [14].

Baskılı ve baskısız malzemeler üzerine $10-50 \mu$ arası kalınlıkta uygulanabilen baskılı baskısız malzemeleri sıvılara, sürtünmelere, katlamalara karşı koruyan, gıdalara hijyenik bir ortam sağlayıp malzemeye mukavemet sağlayarak ömrünü uzatan ve estetik ürünleri ortaya çıkartmak için kullanılan yöntemidir [15, 16]. Selofan aynı zamanda kartonun katlanmasında karton yüzeyinin elastikiyetini arttırarak, karton yüzeyinde oluşabilecek çatlamaları önlemesi nedeniyle de sıkça uygulanmaktadır [17].

\section{MATERYAL ve YÖNTEM}

Bu çalışmada; baskı altı malzemesi olarak ortalama aynı kalınlık ve beyazlık değerinde kroma kartonlar kullanılmıştır. Yüzey karakterizasyonlarının tespiti amacıyla öncelikle bu kağıtların yüzey düzgünlüğü özellikleri ölçümlenmiştir. Öncelikle ölçümlenecek kriterlerin belirlenerek bu özelliklere uygun test skalası hazırlanmıştır. Baskıaltı malzemesinin seçiminde standartlara uygun ve karton ambalaj üretiminde yaygın olarak kullanılan kroma karton belirlenmiştir. Kroma kartonun gramajı ise, görsellik gerektiren ürün ambalajlarında kullanılan 280g/m2 ağırlığında seçilmiştir. Daha sonra baskıda aşağıda özellikleri verilen baskı mürekkepleri kullanılarak baskılar ISO standartlarında gerçekleştirilmiştir. Baskı makinesi firmanın standart üretim hızına getirildikten sonra 1.000 adet baskı yapılmıştır. Yapılan baskılar üzerinden gözle kontroller yapılarak, densitometrik ve spektral cihazlarla ölçümleri gerçekleştirilmiştir. Ölçüm sonucu elde edilen bulgular karşılaştırmalı olarak incelenmiş ve değerlendirmeleri yapılmıştır.

Baskıaltı Malzemesi: Avrupa Standartlarına göre GD-2 Kroma kartonun üst katına kuşe uygulanmıştır. Alt katı gri renkli olup 95,6-97,1 \% oranında geri dönüştürülmüş kağıttan üretilmiştir. Kroma kartonun ISO 2470 beyazlık, ISO 2493 stiffness, ISO 536 gramaj, ISO 534 kalınlık ölçümü değerleri ortalamaları alınarak gerçekleştirilen sonuçları Tablo.1' de gösterilmişstir.

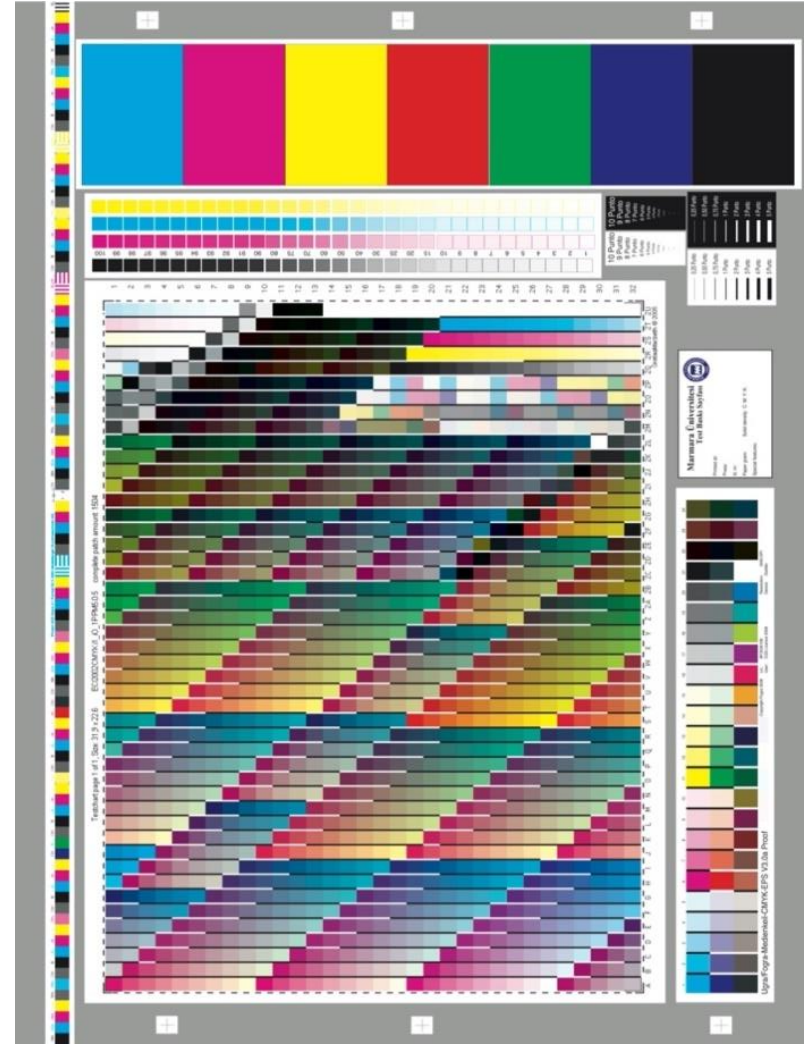

Şekil 1. Test Skalası

Mürekkep: Karton üzerine yapılan baskılar; Toyo UV process cyan, magenta, sarı ve siyah tabaka ofset mürekkepleri kullanılarak gerçekleştirilmiştir. TOYOINK UV process seri mürekkeplerin teknik özellikleri Tablo.2 ' de gösterilmiştir.

Baskı Makinesi: Hazırlanan test kriterlerine uygun baskılar üretim şartları değiştirilmeden standart şartlarda, KBA Rapida 142 ofset bask1 makinasında, ISO 12647-2 standardına uygun olarak optimum bask1 odası fizikokimyasal şartlarında gerçekleştirilmiştir. Test baskıları yapılmadan önce kağıtlar baskı odasında $23 \pm 1{ }^{\circ} \mathrm{C}$ ve $\% 50 \pm 3 \%$ bağ 1 l nemde 24 saat şartlandırılmıştır.

Ölçüm Cihazı: Densitometrik ve spektral ölçümleri Reflection ölçümleme yapabilen X-Rite eXact Advanced cihazı ile; D50 aydınlatma, $2^{\circ}$ gözlemci, 0/45 veya 45/0 geometri, siyah fon ölçüm koşullarında gerçekleştirilmiştir.

Tablo 1. Bask1 alt1 malzemesinin özellikleri

\begin{tabular}{llrrr}
\hline & Birim & \multicolumn{1}{c}{ Değer } & Tolerans & Ölçüm Standardı \\
\hline Gramaj & $\mathrm{g} / \mathrm{m}^{2}$ & 280 & $\pm \% 3$ & ISO 536 \\
Kalınlık & $\mu \mathrm{m}$ & 350 & $\pm \% 5$ & ISO 534 \\
Yüzey Düzgünlüğü & $\mu \mathrm{m}$ & 2 & 0,5 & ISO 8791-4 \\
Beyazlık (üst) & $\%$ & 82 & $-1 \%$ & ISO 2470 \\
Boy Stiffness & $\mathrm{mNm}$ & 10,2 & $-15 \%$ & ISO 2493 \\
En Stiffness & $\mathrm{mNm}$ & 5,3 & $-15 \%$ & ISO 2493 \\
Ortalama Stiffness & $\mathrm{mNm}$ & 7,4 & $-15 \%$ & ISO 2493 \\
\hline
\end{tabular}


Tablo 2. Baskı mürekkebi teknik özellikleri

\begin{tabular}{ccccc}
\hline & Işı Haslı̆̆ & Alkol & Nitro & Alkali \\
\hline Cyan & 8 & + & + & + \\
Magenta & 5 & + & + & - \\
Sarı & 5 & + & + & + \\
Siyah & 8 & + & + & + \\
\hline
\end{tabular}

Tablo 3. Spektral Densitometre Ölçüm Cihazı Teknik Özellikleri

\begin{tabular}{lc}
\hline & Teknik Özelllikleri \\
\hline Ölçüm & $45 ; / 0$ i ISO 5-4:2009(E) \\
Iş1k Cinsi & Gas filled tungsten,UV LED \\
Ölçüm Koşulları & M0, M1 (part 1), M2, M3 \\
Spektral Aralık & 400 to 700 nm \\
Renk Fark1 & CIE ÆE* (1976), (2000), (1994) \\
Renk Uzayı & CIE L*a*b*, CIE L*C*hi, CIE XYZ \\
Iş1k Kaynağ1 & $\mathrm{A}, \mathrm{C}, \mathrm{D} 50, \mathrm{D} 55, \mathrm{D} 65$, \\
Gözlemci Açı1 & $2 ;$ and $10 ;$ \\
\hline
\end{tabular}

Renk evreni için test skalası taraması ise; X-Rite i1iO Automated Scanning Table ile gerçekleştirilmiştir.

Basılmış numuneler üzerine uygulanan selofan sonrasında da densitometrik ve spektrofotometrik değişimine etkileri uygulamalı olarak incelenmiştir.

Selofan uygulamasında, 28 mikron kalınlığında bir film ve $365 \mathrm{~mm}$ genişliğinde laminasyon yapabilen ve ayarlanabilir hızda ve derecede kullanılabilen eşit 1S1 dağılımlı krom merdaneye sahip bir selofan makinesi kullanılmıştır.

\section{BULGULAR ve TARTIŞMA}

Yapılan çalışmada, ölçümler sonucunda selofansız, mat selofan ve parlak selofan uygulanmış kartonların üzerindeki mürekkep densitesinin karşılaştırmalı değerleri Şekil 2'de verilmiştir. Şekil 2'de görüldüğü gibi, karton üzerine uygulanan selofan uygulamaları mürekkep densitelerinde artmaya neden olmuştur. Parlak selofan uygulamasının mat selofan uygulamasına göre densiteyi daha çok etkilediği belirlenmiştir. Özellikle Magenta ve Sarı (Yellow) renklerde bu farkın daha fazla olduğu ölçülmüştür.

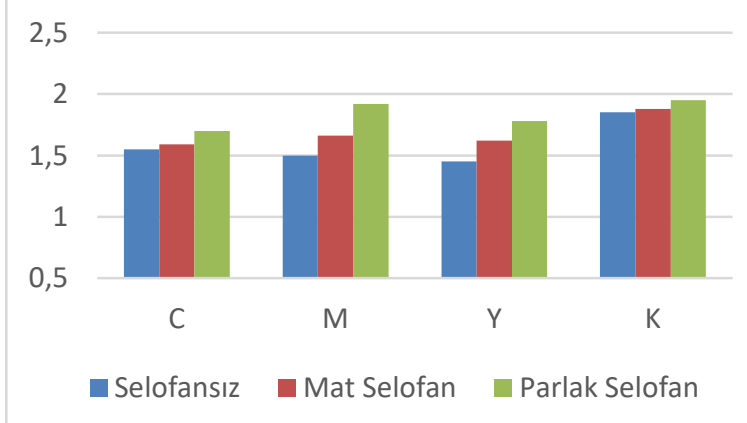

Şekil 2. Selofansız, mat selofan ve parlak selofan uygulanmış baskıların mürekkep densite değerleri
Mat ve parlak selofan kaplanmış baskıların selofan kaplanmamış baskıların renk değerleri ile karşılaştırıldığında; $\Delta \mathrm{E}$ renk farkının en fazla yellow (sarı) ve magenta renlerinde gerçekleştiği, cyan ve özellikle siyah renklerde renk farkının daha az olduğu belirlenmiştir. Parlak selofan uygulamasının neden olduğu renk değişimi ( $\Delta \mathrm{E}$ renk farkı) mat selofana göre daha fazla gerçekleşmektedir.

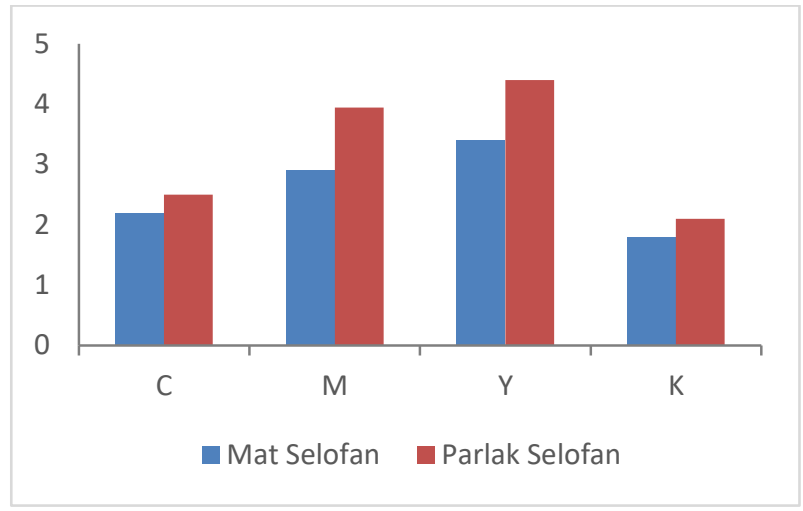

Şekil 3. Selofansız, mat selofan ve parlak selofan uygulanmış baskıların $\Delta \mathrm{E}$ Renk farkları

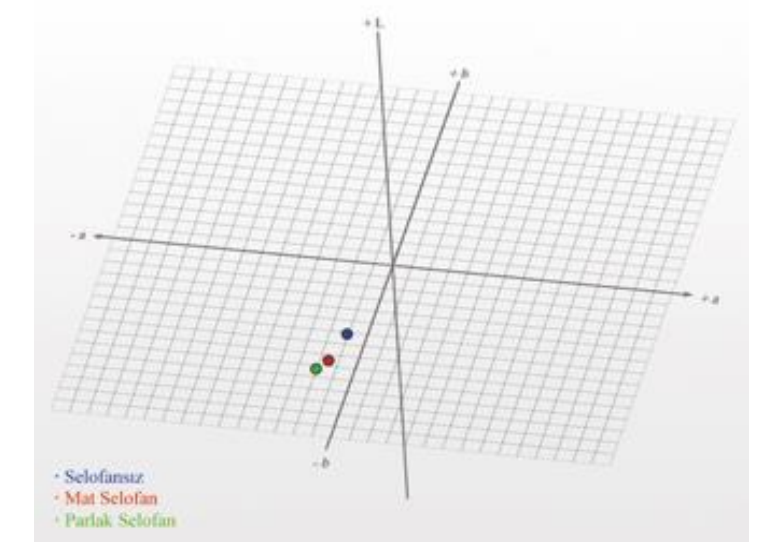

Şekil 4. Selofansız, mat selofan ve parlak selofan Cyan 3D $\mathrm{L} * \mathrm{a} * \mathrm{~b} *$ renk düzlemindeki yerleri.

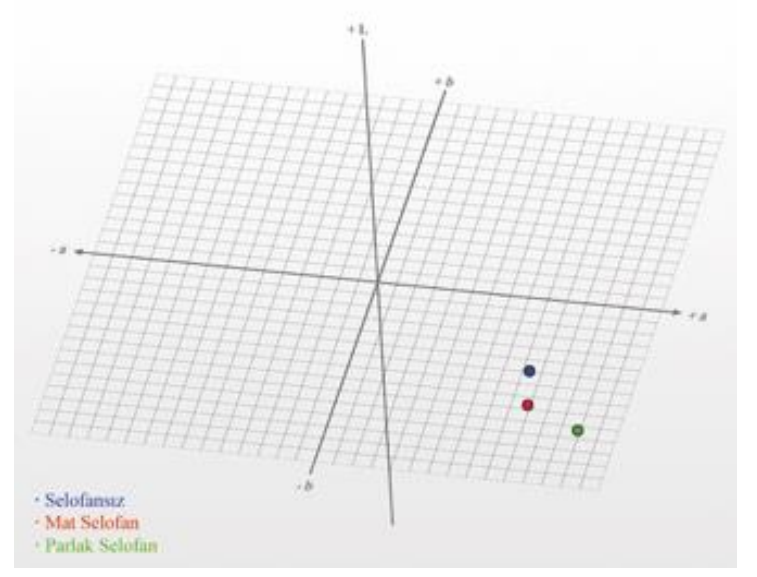

Şekil 5. Selofansız, mat selofan ve parlak selofan Magenta 3D $\mathrm{L} * \mathrm{a} * \mathrm{~b} *$ renk düzlemindeki yerleri. 


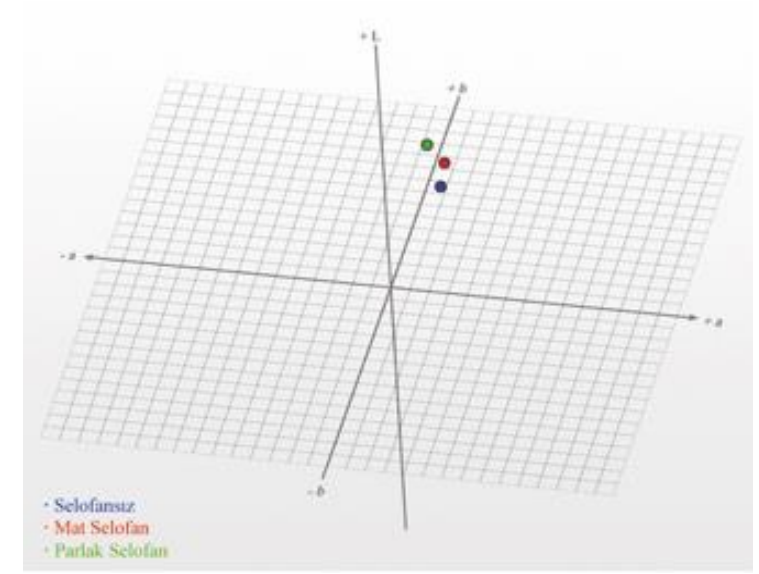

Şekil 6. Selofansız, mat selofan ve parlak selofan Yellow 3D $\mathrm{L} * \mathrm{a} * \mathrm{~b} *$ renk düzlemindeki yerleri.

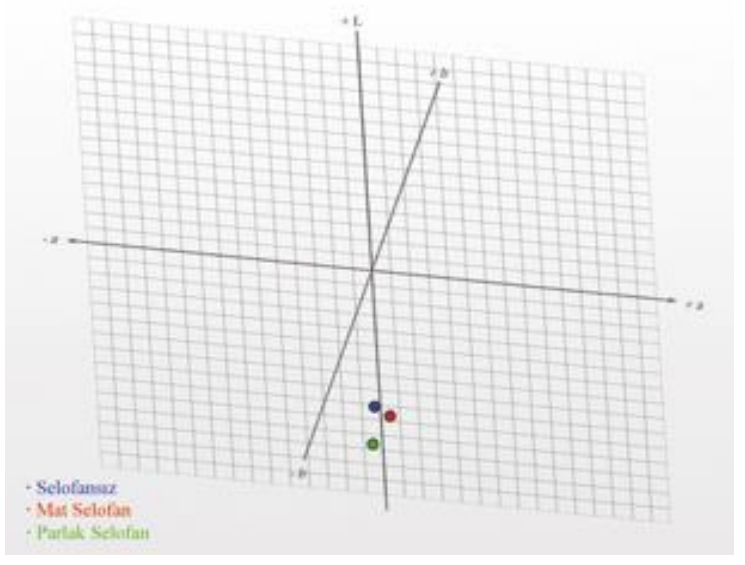

Şekil 7. Selofansız, mat selofan ve parlak selofan Yellow 3D $\mathrm{L} * \mathrm{a} * \mathrm{~b} *$ renk düzlemindeki yerleri.

\%80'lik noktaların, nokta kazancı değerleri Şekil 6'da görüldüğü gibi, mat ve parlak selofan artmaktadır. Mat selofan uygulamasının parlak selofana göre daha fazla nokta kazancına neden olduğu görülmektedir. Cyan, magenta, yellow ve black renklerindeki nokta kazançlarında ise; en çok farkın yellow renginde olduğu en az artışın ise cyan renginde olduğu tespit edilmiştir

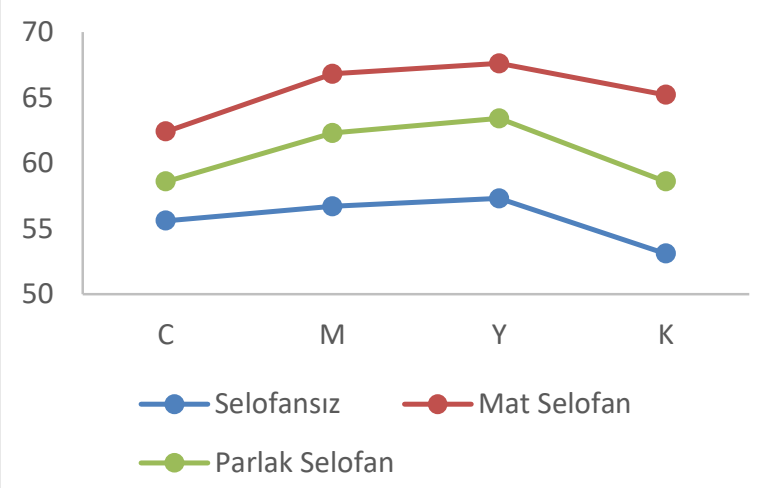

Şekil 8. \%40'llk noktanın Selofansız, Mat ve Parlak Selofan uygulaması sonrası nokta kazancı değerleri

\%80'lik noktaların, nokta kazancı değerleri Şekil 8'de görüldüğü gibi, mat ve parlak selofan artmaktadır.

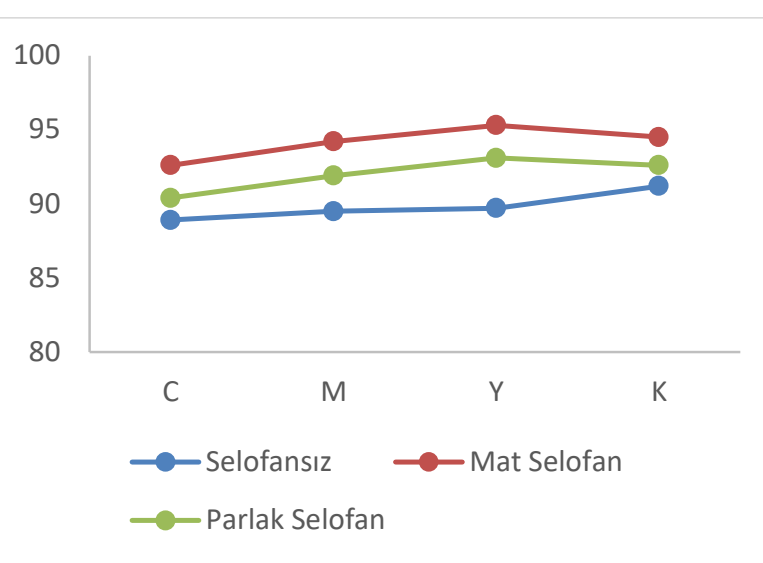

Şekil 9. \%80'lik noktanın Selofansız, Mat ve Parlak Selofan uygulaması sonrası nokta kazancı değerleri

Mat selofan uygulamasının parlak selofana göre daha fazla nokta kazancina neden olduğu görülmektedir. Cyan, magenta, yellow ve black renklerindeki nokta kazançlarında ise; en çok farkın yellow renginde olduğu en az artışın ise cyan renginde olduğu tespit edilmiştir. Uygulama sonrası taranan test skalaları ile elde edilen renk evrenleri Şekil 10 ve Şekil 11 'de karşılaştırmalı olarak verilmiştir. Selofan uygulamasına dayanıklılık özelliğini sağlayan Nitro dayanımı olan mürekkeplerle yapılan bu baskılar üzerine selofan kaplanmasının, elde edilen renk evrenini genişlettiği görülmektedir. Renk evrenleri incelendiğinde; en dar renk evreni selofan kaplanmamış baskıya, en geniş renk evreni ise parlak selofan uygulanmış baskıya aittir. Parlak selofan uygulamasının, selofan kaplanmamış ve mat selofan kaplanmış baskılara göre özellikle sarı, kırmızı ve yeşil tonlarda renk evrenini genişlettiği belirlenmiştir.

$\Delta \mathrm{E}$ renk farklarının, $\mathrm{C}, \mathrm{M}, \mathrm{Y}$ ve $\mathrm{K}$ ana renkleri için $\mathrm{L}^{*} \mathrm{a} \mathrm{b}^{*}$ renk evreni üzerinde hangi eksenlere doğru değiştikleri noktasal olarak değerleri Şekil 5, Şekil 6, Şekil 7'de gösterilmiştir. CMYK ana renklerinin; selofansız karton üzerindeki konumları mat ve parlak selofan uygulamalarına göre daha düşük renk seviyesinde kaldığı ortaya çıkmıştır.

Selofansız, mat selofanlı ve parlak selofanlı uygulamalar üzerinden yapılan ölçümlerde \%40'lık noktaların, nokta kazancı değerleri Şekil 8'de görüldüğü gibi, mat ve parlak selofan sonrası önemli ölçüde artmaktadır. Mat selofan uygulamasının parlak selofana göre, orta tonlar olan \%40'lik noktalarda daha fazla nokta kazancına neden olduğu görülmektedir. Cyan, magenta, yellow ve black renklerinde standartların üzerinde bir nokta kazancı gerçekleşmiştir. En çok farkın yellow renginde olduğu en az artışın ise cyan renginde olduğu tespit edilmiştir.

\section{SONUÇ}

Karton ambalaj baskıları üzerine kaplanan Mat veya Parlak selofan uygulamalarının densite ve nokta kazancı değerlerinde artışa sebep olmaktadır. Orta tonlar olan \%40'lik noktalardaki nokta kazanc1 değerleri \%80'lik noktalardaki nokta kazancına göre daha fazladır. Bu sebeple baskı öncesi nokta eğrileri, orta tonlarda koyu tonlardan daha aşağı değerlere 
çekilerek ton ayarlaması yapılması gerekmektedir. Nitro dayanımına sahip mürekkeplerle yapılan bu baskılarda, özellikle magenta ve sarı renklerde daha fazla, siyah renkte ise daha az renk değişimi olduğu ölçümler ve $\Delta \mathrm{E}$ hesaplaması sonucu belirlenmiştir. Ayrıca bu uygulamaların 3 eksenli grafiklerde CMYK renklerinin $\mathrm{L} * \mathrm{a} * \mathrm{~b} *$ eksenlerinde hangi noktaya taşıdığ 1 analiz edilebilir duruma getirilmiştir. Magenta ve sarı renklerin cyan ve siyah renklere göre daha yoğun olduğu görüntülerde, magenta ve sarı renklerin renk dengeleri (color balance) görüntü işleme programlarında, ana renk yoğunluğunun renk karışımları şekline dönüştürülerek ayarlanması oluşan renk farklılığını azaltacaktır.

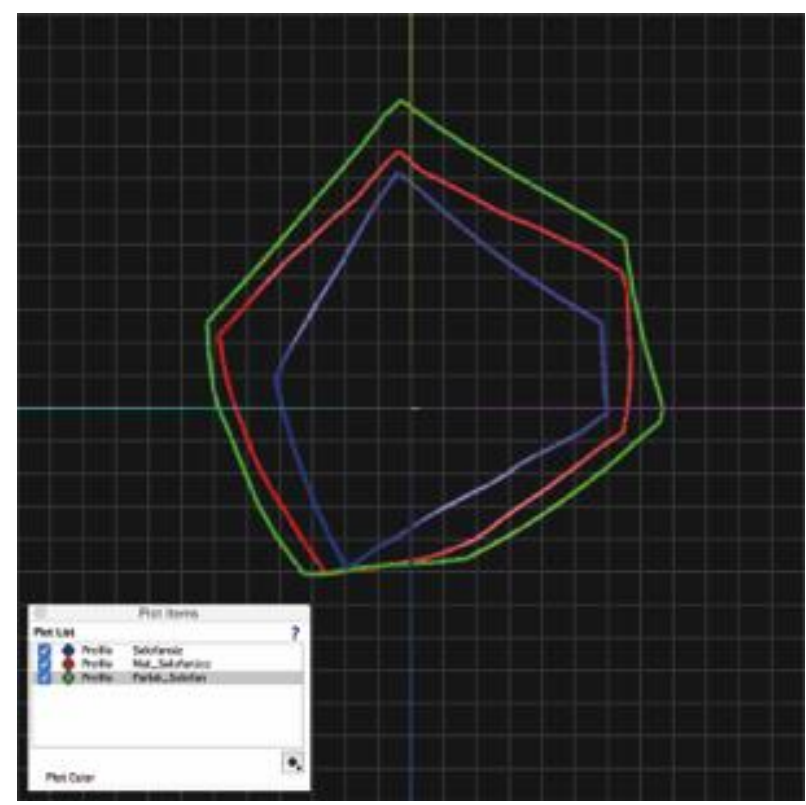

Şekil 10. Selofansız, Mat ve Parlak Selofan uygulamalarının 2 boyutlu renk evreni (Mavi: Selofansız, Kırmızı: Mat Selofan Kaplanmış, Yeşil: Parlak selofan Kaplanmış)

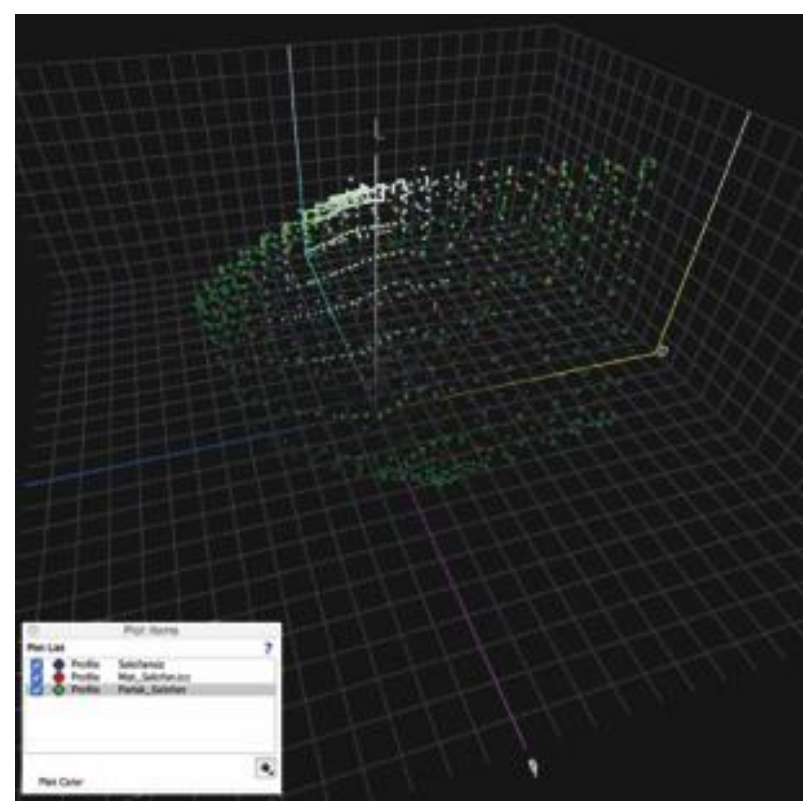

Şekil 11. Selofansız, Mat ve Parlak Selofan uygulamalarının 3 boyutlu renk evreni
Parlak selofan uygulaması, mat selofana ve özellikle selofan kaplanmamış baskılara göre renk evrenini daha fazla genişletmektedir. Tüketicinin satın alma davranışlarına olumlu etkisi olan renk canlılığının, karton ambalaj baskıları üzerine uygulanacak mat ve parlak selofan uygulamaları ile arttığı renk evrenlerinin belirlenmesi ile de kanıtlanmıştır.

\section{KAYNAKÇA}

[1] Elwan A.A. Influence of Ink Viscosity level on Tone Value Increase in Sheet-fed Offset Printing, International Design Journal, 7:2 307-312, 2017.

[2] Özomay Z. Kağıt ve Karton' un Yapısal Özelliklerinin Basılabilirlik Parametrelerine Etkisinin İncelenmesi, Marmara Üniversitesi Fen Bilimleri Enstitüsü, Doktora Tezi, 2016

[3] Kumar R. 4M Model of Sheet Fed Printing Machine: A Case Study of ITC Limited, Chennai, International Journal of Science, Engineering and Computer Technology, 7:2 156-159, 2017.

[4] Kitakubo S. Some Characteristics on Human Visual Sensitivity for Spatial Frequency of Digital Halftone Images, Proc. NIP21, p.118-121, 2005.

[5] Özomay Z., Aydemir C., Özakhun Ş.C. Determination Of The Most Suitable Option For Production With Uncoated Papers In Offset Printing By Multi-Criteria Decision Making Method, Muş Alparslan Üniversitesi Fen Bilimleri Dergisi, 7:2 667-672, 2019

[6] Kumar S., Saini M. Study of Conventional Offset Printing with Digital Printing, International Journal of Science, Engineering and Computer Technology, 6:2 110-112, 2016.

[7] Joshi A. Analysis of SID and Dot Gain in Relation to Surface Characteristics of Coated Uncoated Paper in Sheet-Fed Offset and Digital Printing Machines, International Journal of Science, Engineering and Computer Technology, 6:1 43-44, 2016.

[8] Cai-Yin W., Xiang-Wei K., Chao L. Process color watermarking: the use of visual masking and dot gain correction, Multimedia Tools and Applications, 76:15 16291-16314, 2016.

[9] Ural E., Özomay Z., Özdemir L. Palm Yağ1 Katk1lı Mürekkeplerin Baskı Kalitesine Etkisinin Belirlenmesi, Muş Alparslan Üniversitesi Fen Bilimleri Dergisi, 6:1 533-537, 2018.

[10] Özomay Z. IGT test bask1 makinesi ile ofset bask1 makinesi arasındaki renk uyumu için optimum prosedürün hazırlanması, Marmara Üniversitesi Fen Bilimleri Enstitüsü, Yüksek Lisans Tezi, 2009.

[11] Kurt M.B., Mumcu Y.K., Özdemir L. Estimation Of Screen Density According to Different Screening Methods With Artificial Neural Network Method In Flexo Printing System, Politeknik Dergisi, 21:3 575-580, 2018.

[12] Şahin C., Özomay Z., Keskin B. Gazete Kağıdında Baskı Basıncının Nokta Kazancına Etkisinin Değerlendirilmesi, Electronic Journal Of Vocational Colleges 3 121-128, 2013.

[13] Zelzele Ö., Özdemir L. Dijital Termal Flekso Bask1 Kalıbı Hazırlama Parametrelerinin, Kalıp Üzerindeki Nokta Yapısına Etkisinin İncelenmesi, Marmara Fen Bilimleri Dergisi, 27:2 63-75, 2015.

[14] Escher S., Strafe T. Robustness Analysis of a passive printer identification scheme for halftone images, IEEE International Conference on Image Processing, pp. $4357-$ 4361, 2017. 
[15] Parag M.M., Bandyopadhyay, S. Correlation of ink viscosity and printability in offset lithography process on paperboard used in packaging, Acta graphica: znanstveni časopis za tiskarstvo i grafičke komunikacije, 29:3 37-48, 2019.

[16] Özomay, M. Türkiye'de yöresel dokunan bez örneklerinin doğal boyarmaddeler ile gri ilişkisel analiz yöntemi kullanılarak boyama özelliklerinin belirlenmesi, Marmara Üniversitesi Fen Bilimleri Enstitüsü, Doktora Tezi, 2016.

[17] Sharma D.K., Rani R. Analysis of the Relationship between Solid Ink Density, Dot Gain and Print Contrast in Digital Printing. International Journal of Science, Engineering and Computer Technology, 6:2 130-131, 2016. 